\title{
Building community social capital
}

\section{John Durston}

Social Affairs Officer,

Social Development Division,

ECLAC.
Social capital means the set of norms, institutions and organizations that promote trust and cooperation among persons in communities and also in wider society. In those formulations of the social capital paradigm (and of the neoinstitutional economics on which they are partly based) which focus on its collective manifestations, it is claimed that stable relationships based on trust and cooperation can reduce transaction costs, produce public goods and facilitate the constitution of social actors and even of sound civil societies. Community social capital is a particular form of social capital which comprises the informal content of institutions that aim to contribute to the common good. Even some of the foundational authors of the social capital paradigm have doubts about the feasibility of creating such capital in groups where it does not already exist. The peasant communities of Chiquimula (Guatemala) covered by the anti-poverty "Support Project for Small-scale Producers of Zacapa and Chiquimula" (PROZACHI) displayed a relatively individualistic culture of dependence and domination yet at the same time had a broad and dynamic repertoire of various norms, including some which could serve as a symbolic support for solidary and reciprocal practices. Chiquimula seemed to lack social capital institutions, but with the recovery of institutional practices of the past and the emergence of new contexts and opportunities for developing new group strategies it has been possible to create social capital in these communities, with external support and training, and thus turn an excluded sector into a social actor on the micro-regional scene. 


\section{Social capital}

\section{A useful conceptual tool}

A vigorous debate is currently under way in academic circles and also in development agencies on the theory of social capital. This emergent paradigm aims to be a kind of unified theory incorporating concepts from different fields, such as reciprocity, social networks, participatory development and governance. It promises to be a valuable tool for the analysis and promotion of peasant-level development. The term "social capital" embraces the norms, institutions and organizations that promote trust and cooperation among persons, in communities and also in wider society. In those formulations of this concept (and of the neoinstitutional economics on which they are partly based) which focus on its collective manifestations, it is claimed that stable relationships based on mutual confidence and cooperation can reduce transaction costs (Coase, 1937), produce public goods (North, 1990) and facilitate the constitution of social actors and even sound civil societies (Putnam, 1993a).

This article analyses a particular form of social capital -community social capital- and the possibility of creating it where it does not already exist in order to overcome the poverty and political exclusion of rural communities in Latin America.

In the definition followed here, cultural norms of mutual trust and interpersonal networks of reciprocity are "precursors" of the institutions - more complex and guided by norms of common well-beingwhich constitute community social capital and which spring from those precursors at the level of the community or social system. Some authors consider that social capital is made up of all the interpersonal links that can activate an individual, corresponding to what were already known as diffuse self-centered networks of reciprocity, while at the other extreme the

$\square$ The author wishes to express his thanks for the valuable comments made by Eugenio Lahera, Gonzalo Falabella, Samuel Morley, Maximiliano Cox, Roberto Guimarães, Orlando Peralta, Mario Chamalé, Alejandro Medina, Juan Sáez, Fernando Bazúa, Brent Metz, Fernando Rello, Margarita Flores, Iván Finot, Otto Fernández, Juan José Santibáñez, Rodrigo Contreras and Anthony Bebbington. definition of community social capital (from the neoinstitutionalist standpoint) given by Putnam and North -according to which social capital is what gives rise to cooperation and civism, so that if there is civism there will be social capital- has rightly been described as tautological (Portes, 1998; Portes and Landholt, 1996).

In contrast, what we are maintaining in this article is that: i) community social capital is not an individual resource but a form of social institutionality (of the group, in this case the local community), and ii) the (explicit or implicit) participants in community social capital have the common good as their objective, even though this may not be achieved. Furthermore, unlike formal institutions for the common good (such as cooperatives, for example), which exist "on paper", community social capital is made up of norms, practices and interpersonal relations which exist and can be observed. It is the informal institutionality inside and outside the formal organizations, at the level of the community or broader social system, that determines how such organizations work in practice: what Firth (1963) called "social organization".

Although the members of the community in which community social capital exists shaer a discourse of cooperation for the common good, empirical observation is needed in order to see whether this objective is actually attained, for community social capital and interpersonal reciprocity may cause effects which run counter to the common good, as in the case of some ethnic or religious communities whose practices are exclusive or do not respect fundamental human rights.

Finally, the concept of reciprocity is a central element of the social capital paradigm. The anthropological treatment of this matter has been constructed on the basis of the classic study Essai sur le don by Marcel Mauss (published in 1950), ${ }^{1}$ which had an enormous impact on that discipline from the $1950 \mathrm{~s}$

\footnotetext{
${ }^{1}$ An English version of this essay (Mauss, 1990) is listed in the bibliography below.
} 
on. ${ }^{2}$ he importance of reciprocity goes beyond its presence in "diadic" relations between two persons (Foster, 1961): as a ruling principle it also extends to formal and informal institutional relationships at the community level. In his essay, Mauss notes that in pre-mercantile societies (and to a lesser extent also in our own societies, outside the ambit of the market) there are systems of exchanges based on gifts (objects, aid, favours) which must be repaid, but not necessarily immediately or always in precisely equivalent terms, unlike mercantile transactions (Mauss, 1990). In a socially delimited environment (a traditional society or most present-day peasant communities) with long-term relationships established through a large number of past interactions and a long-term perspective, relations tend to take place at the same moment between the same persons and families in all areas and all institutions of human life (religious, juridical, political, family and economic): in this sense, they are "total phenomena" (Mauss, 1990). For this reason, although reciprocity might at first sight seem to be a minor social phenomenon among many others, it is in fact the basis of social capital institutions in contexts like that of a peasant community.

\section{Doubts about the constructability of social capital}

Strangely enough, even some of the foundational authors, such as Robert Putnam, have doubts about the feasibility of creating social capital in groups where it does not already exist. Thus, for example, Putnam (1993a, p. 184) finally decides that "where institution-building is concerned, time is measured in decades" while the process of changing norms of reciprocity and values of civic engagement "probably moves even more slowly".

This pessimistic view reflects a belief in feedback mechanisms that constantly strengthen existing norms and forms of behaviour, bringing all socio-cultural systems to either a positive social equilibrium in which social capital is built up, or to a negative "acivic" society. According to Putnam, in the "acivic" south of Italy society was trapped for centuries in a repeated negative path in which "mutual distrust and defection, vertical dependence and exploitation ..... have reinforced each other in interminable vicious circles ...." (Putnam, 1993a, p. 181).

\section{II}

\section{The construction of social capital in Eastern Guatemala}

\section{The peasant communities of Chiquimula: an empty institutional landscape?}

Rural communities in Eastern and Western Guatemala are often contrasted in terms similar to the contrasts Putnam makes between the South and North of Italy. There is a widespread perception that the Mayan corporate communities in the western highlands are more oriented towards collective decision-making, whereas those in the eastern lowlands are "individualistic", with little participation in community organizations.

\footnotetext{
${ }^{2}$ Neither Putnam nor North refer to Mauss's essay, which has inspired almost half a century of empirical and theoretical work by anthropologists of a number of countries. So far, not enough use has been made of this store of anthropological wisdom in the debate on social capital.
}

In the 1990s, the "Support Project for the Small-scale Producers of Zacapa and Chiquimula" (PROZACHI) was carried out for seven years in eight municipalities of Eastern Guatemala ${ }^{3}$ with a view to significantly increasing the incomes of poor hillside farmers in an economically, ecologically and institutionally sustainable manner (IFAD, 1998). Its strategy for overcoming poverty was centered on facilitating the peasants' access to bank finance, but it also pro-

\footnotetext{
3 Joint project by the Ministry of Agriculture and Stock-breeding/International Agricultural Development Fund/Organization of Petroleum Exporting Countries/Netherlands. The area of action of PROZACHI covered most of the Department of Chiquimula and also included adjoining areas of two municipalities of the Department of Zacapa. As the great majority of the villages served were in Chiquimula, for reasons of simplicity we will refer to Chiquimula throughout this article.
} 
vided support through its own team of professionals and technicians (in agricultural advisory assistance and technical training, road construction, organization and management, environmental conservation, housing improvement, participation of peasant women in development, marketing, etc.).

When PROZACHI began its activities in 1991, its target group $-5,000$ peasant families cultivating mainly maize and beans in over 130 hillside villages and hamlets- was largely devoid of significant grassroots organizations (FLACSO, 1993). There were a few civic committees, but they were mostly small factions or passive recipients of aid from charitable NGOs. PROZACHI officials were therefore pessimistic and reticent about the possibility of promoting participation by the beneficiaries in taking Project decisions: in short, this was another example of the "acivic" cultures described by Putnam.

\section{Scaling down and scaling up}

It was then observed, however, that the dispersed pattern of human settlement in the hillside hamlets of the PROZACHI area of influence (see maps 1 and 2) corresponded to "local descent groups": that is, networks of kin and neighbours who believe they are descended from a common ancestor (Wolf, 1996). In each village or hamlet the same surnames tended to be repeated in a large proportion of households, and some place names corresponded to the surnames of the purported founders (Durston, 1992). In these local descent groups, which are found in upland areas all over Latin America, residence of newlyweds tends to be virilocal (i.e., near the husband's parents) and interconnected multiplex ties of reciprocity based on close kinship lead to both horizontal and vertical trust and cooperation.

MAP 1

Guatemala: Location of PROZACHI's area of influence

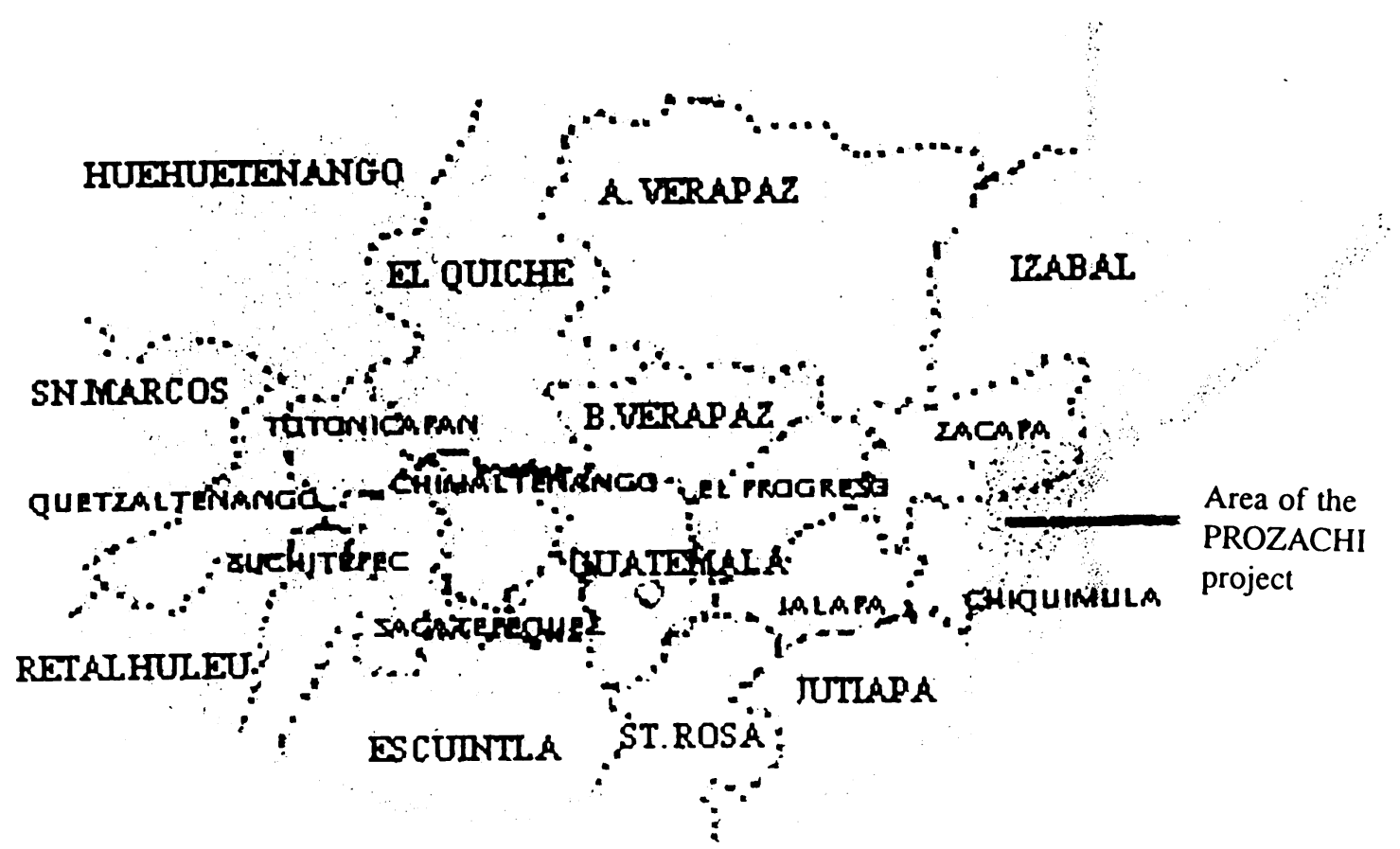

Source: IFAD (1998). 


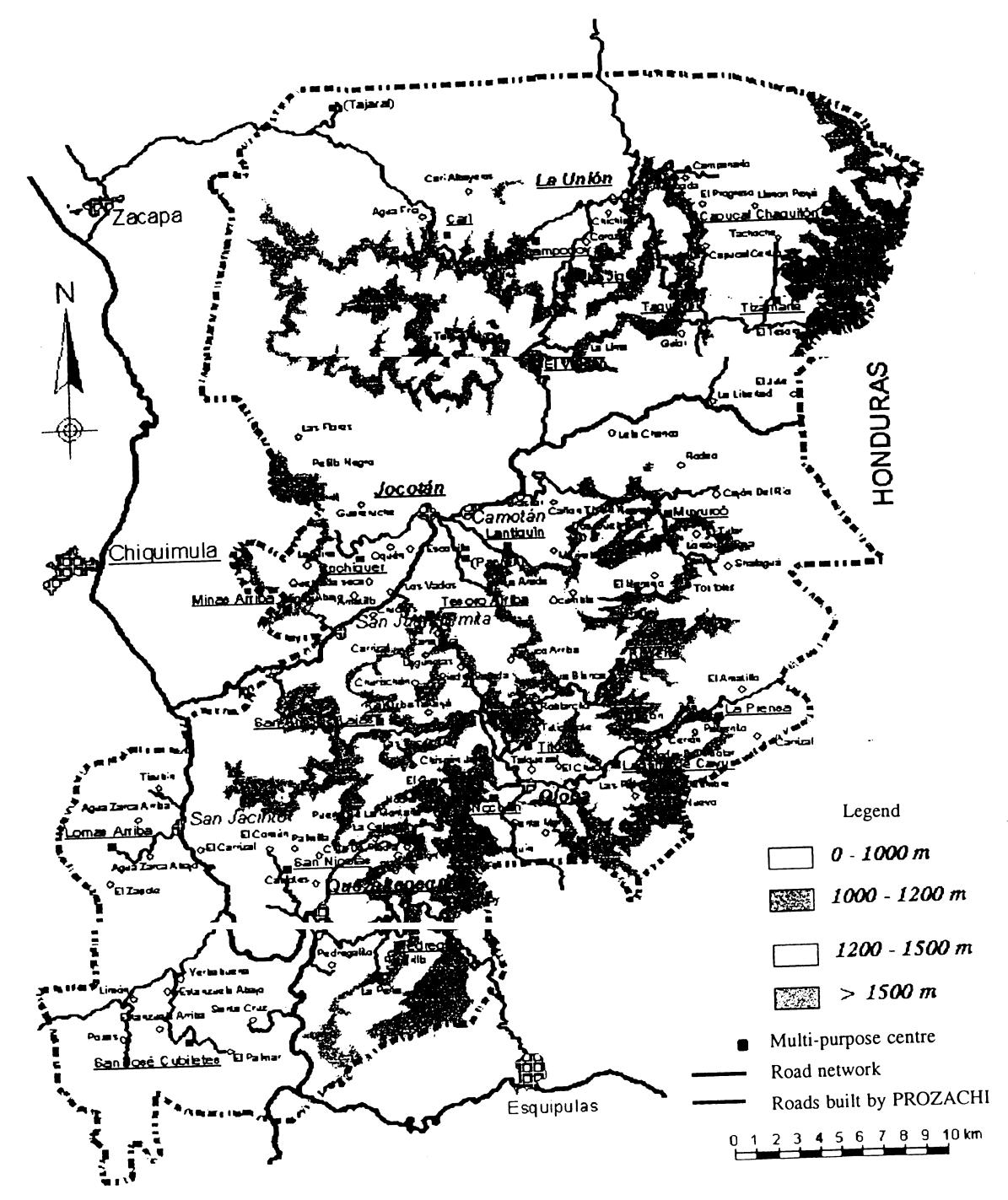

A Guatemalan anthropologist, Hugo Zelaya, was hired to activate work in the field of "participatory planning", and he designed a system of core groups (Grupos Núcleo) -7 to 12 households united by close neighbourhood- to participate in determining the needs and priorities of those gaining access to the services and benefits offered by the Project (see PROZACHI, 1995). Some 40 rural development promotion workers, immersed in the hillside villages, promoted house-to-house the benefits of participating in the exercise. Each core group selected two leaders to moderate their meetings and serve as liaison with PROZACHI. Over 400 core groups were formed, and became the source of proposals for modifying the annual operating plan of the Project. 
The period of most intense growth of the core groups coincided with a big increase in the number of households receiving credit: from 525 in 1992 to 3,676 in 1994. Although there were several factors which combined to bring about these changes, Project staff and peasants agree that the creation of these core groups were largely responsible for this.

After three years of activity of the core groups, an assembly of their representatives proposed the establishment of coordination mechanisms at the multi-village level as a more efficient way of working. An advisory study designed a system of community councils incorporating all the committees and organized groups, building upon the previous grass-roots groundwork but largely replacing the small interfamily groups as the most frequent instances of civic participation. Initiatives by PROZACHI staff began to take a back seat to spontaneous proposals by the peasants on support for the organization and its concrete actions.

The number of specific interest groups, such as drinking water supply committees or cooperative micro-enterprises, increased by $28 \%$ between 1991 and 1998 (table 1). Over a hundred community councils and eight municipal coordinating committees were formed, and what seems even more important is that $56 \%$ of these community organizations were evaluated as having medium or high levels of self-management capability (table 2). Finally, in the first quarter of 1998 a regional* association of representatives of these rural community organizations was set up and began to play a role in the establishment of rural development priorities in the region.

\section{Roots of social capital in Chiquimula}

Looking back, there are various aspects of the social capital formation process in Chiquimula which help to explain how it was possible to construct such capital in that "acivic" region in a much shorter space than the decades foreseen by Putnam. The first of these factors was the existence of the local descent groups, which were repositories of reciprocity and precursors of the core groups.

* Throughout this article, "region" and "regional" refer to the local, micro-regional level.
TABLE 1

Chiquimula and Zacapa (Guatemala):

Growth of peasant organizations at

five territorial levels, 1991-1998

\begin{tabular}{lrr}
\hline Territorial level & 1991 & 1998 \\
\hline $\begin{array}{l}\text { Local descent groups } \\
\text { (village level) }\end{array}$ & - & 440 \\
$\begin{array}{l}\text { Specific interest groups } \\
\text { Community level }\end{array}$ & 380 & 487 \\
(inter-village level) & - & 129 \\
Municipal level & - & 8 \\
Regional level & - & 1 \\
\hline
\end{tabular}

Source: Support Project for Small-Scale Producers of Zacapa and Chiquimula (PROZACHI).

TABLE 2

Chiquimula and Zacapa (Guatemala):

Organizational consolidation in

participating communities, 1998

\begin{tabular}{|c|c|c|c|c|}
\hline \multirow{2}{*}{ Area } & \multirow{2}{*}{$\begin{array}{l}\text { Number } \\
\text { of } \\
\text { villages }\end{array}$} & \multicolumn{3}{|c|}{$\begin{array}{l}\text { Level of autonomy } \\
\text { (Number of villages) }\end{array}$} \\
\hline & & Incipient & $\begin{array}{l}\text { Interme- } \\
\text { diate }\end{array}$ & $\begin{array}{l}\text { Consoli- } \\
\text { dated }\end{array}$ \\
\hline Jocotán & 49 & 14 & 17 & 18 \\
\hline Olapa & 35 & 18 & 13 & 4 \\
\hline La Unión & 19 & 11 & 3 & 5 \\
\hline Quezaltepeque & 26 & 14 & 12 & - \\
\hline Total & 129 & 57 & 45 & 27 \\
\hline Percentgage & 100 & 44 & 35 & 21 \\
\hline
\end{tabular}

Source: Support Project for Small-Scale Producers of Zacapa and Chiquimula (PROZACHI).

A second factor was the shared identity of the inhabitants. Although the peasantry of Eastern Guatemala is usually conceived of as being "ladino" (non-indigenous), barely a generation ago social institutions based on Ch'ortí Mayan lineages predominated in most of the hillside communities, and the Ch'ortí language is still spoken in a number of villages. In the 1994 census, over 70,000 residents of the Department of Chiquimula identified themselves as Ch'ortí. The consciousness of these roots and the strengthening of the Ch'ortí language and culture have been furthered by the national Maya movement since the mid-1990s (Metz, 1998). Other elements strengthening their identity is that they are all "peasants", all come from the same area, and belong to the 
same community. Thus, while the identities of the Chiquimula hillside villagers are mixed and varied, they all see themselves as the opposite to the dominant urban dwellers, and this serves as a source of cohesion and trust among the members of the different rural communities.

The third factor was memories of the past. In the 1960s the Belgian Catholic Mission established a number of agricultural cooperatives and self-help infrastructure development committees in villages which were visited by PROZACHI three decades later. Though repressed during the late 1960 s, those organizations were remembered by the peasants when discussing the pros and cons of participating in the new organizations promoted by PROZACHI.

The fourth factor was indeed the reduction of repression. In the 1990s the Army began to gradually withdraw from direct participation in political decision-making at the national level: a process that culminated with the signing of the peace accords in late 1996. In Chiquimula, the village "Comisionados Militares" and "Patrullas de Autodefensa Civil" ceased to exist as such, and the regional army base was shut down, so that the structural situation became much more favourable for peasant organizations.

The fifth factor was the initiation of the process of empowerment of peasant women. The registration of hundreds of women in the Civil Register for the first time, with the support of PROZACHI, the formation of women's production groups, aided with credit and advisory assistance (Lundius, 1998), and their incorporation into community discussions set loose and trained human resources which had previously been excluded. These changes strengthened the process of self-diagnosis and the democratization of leadership, which are essential elements of social capital.

The sixth factor was the interaction of peasants with the rural development promoters, who lived in the midst of the villages and whose presence in the local and regional social environment was scheduled to last for several years. The promoters naturally participated in the "total service systems" and in the reciprocal relations which Mauss described. This gave rise to stable relationships, strengthened by the expectation of future interactions and by the affective links that arose from the past history of practices of mutual aid and the return of such favours at other times (see Evans, 1996). On the one hand, the personal commitment shown by the promoter to the members of the community stimulated the participation of peasants in PROZACHI's activities, which thus gained in prestige, while on the other hand the various forms of aid given by the promoters strengthened the relations of reciprocity and solidarity among the inhabitants of the area themselves.

The above six factors contributed to the creation of social capital, but the materialization of its potential was due to the initiatives of PROZACHI and, as from March 1997, of the Social Investment Fund (FIS). ${ }^{4}$ Firstly, training programmes were designed in order to create social capital by strengthening social skills and capabilities in the fields of diagnosis, communication and planning. By 1995, at the request of villagers themselves, over 400 organizational training "events" per year were being held. In order to do this it was necessary to adapt the available methods and materials to local conditions, to design new techniques, and to publish a series of pamphlets for group discussion.

SECONDLY, PROZACHI AND FIS gave peasants the opportunity to exercise these new-found skills and social capital associations to obtain direct material benefits from the Project and FIS. Thirdly, both PROZACHI and FIS protected the peasants' embryonic community social capital institutions while authoritative clientelism was still present in the region and intervened when they were threatened by hostile social actors.

\footnotetext{
${ }^{4}$ FIS provides physical social infrastructure (mainly roads, schools and health centres) to organized rural communities without cost to them.
} 


\section{III}

\section{Lessons for social capital building}

The analysis made here of the Chiquimula experience suggests a need for some revision of the social capital paradigm with regard to the obstacles for the construction of such capital, and these theoretical modifications have their own policy implications.

Firstly, trust and reciprocity that go beyond the nuclear household and are to be found in the local descent groups are associated with close kinship ties and long-time interaction with neigbours and appear to be found in all peasant societies everywhere (see Wilson, 1997).

Secondly, and in line with more modern game theory, the frequent repetition of exercises requiring trust and cooperation among peasants has created a growing disposition -slow and uncertain to begin with, but later faster- to cooperate reciprocally in community life (Axelrod, 1997). Confidence is built on the past, not on the future: on experience of past fulfillment which shows people's trustworthiness, not on agreements and promises for the future. In situations where past conflict had undermined trust (as in Chiquimula), these cooperation exercises have created a recent history of trustworthiness as the basis for future collaboration.

Thirdly, vertical reciprocity has proved to be a necessary part of social capital building, both inside and outside the community. Almost all social capital theorists consider that vertical reciprocity relationships represent the opposite to social capital, because they involve people of unequal power and are therefore asymmetrical. However, the distinctions between vertical and horizontal reciprocity are not so clear-cut in real life.

\section{Vertical reciprocity among peasants as a basis for social capital}

In the peasant communities of Chiquimula, some household heads, especially older ones, lead multi-household groups -or less clearly-defined "quasi-groups" (Mayer, 1966)- of kin and neighbours that serve to accumulate both wealth and prestige. Thus, on the one hand vertical reciprocity and factionalism are intrinsic to the interpersonal net- works of peasant communities, but on the other hand the leadership based on this vertical reciprocity can be the basis for cooperation and scaling-up the organization beyond the local village level. These leaders of quasi-groups are entrepreneurs of social capital, managing the human resources of their kin and neighbours, to whom they are in turn accountable.

In Chiquimula, the social skills and cooperation practices developed in the core groups were passed on by their leaders at the regional level, where these representatives negotiated with their peers from other organizations. Ultimately, the techniques for creating cooperation also helped to scale up peasant organization. These new leaders, formed in the core groups, ${ }^{5}$ and the regional coordinators elected from among them, also created a dense communications network within a dispersed social system in which repression had further increased isolation.

\section{Clientelism and vertical reciprocity as bases for social capital}

The vertical clientelism linking the hillside villages of Chiquimula with broader society did not disappear along with the direct military presence but continued to operate in an authoritarian manner, both through local bossism in party politics and through economic relations with landowners and urban middlemen. Even the potential for local social capital creation provided by the reforms aimed at the decentralization of official decision-making and resource allocation served to strengthen local caciques because of their privileged access to those resources and spaces (see Galeano and Yore, 1994). In short, the continued presence of authoritarian clientelism in the area made necessary some form of outside support for the incipient community social capital.

\footnotetext{
${ }^{5}$ Some 800 such groups in PROZACHI's area of influence.
} 
However, such outside support is also a form of semi-clientelism. In this respect, the distinction drawn by Jonathan Fox between authoritarian clientelism and semi-clientelism (Fox, 1996) is highly relevant. In contrast with authoritarian clientelism, the dominant actors in semi-clientelism renounce the use of force and repression, instead furthering their interests by providing needed services to their clients or gaining their allegiance in a negotiated, shared political cause.

PROZACHI and FIS come close to Fox's definition of semi-clientelistic outside agencies. Their staff members identified with the beneficiaries and provided more democratic vertical reciprocity relations which facilitated peasants' access to growing public resources and reformist allies at the central level (see Tendler, 1997). Both these institutions contributed to the process of local and microregional democratization, and their activities were a key factor in creating the necessary conditions for the generation of peasant community social capital. At the same time, they served to strengthen the transformation of reciprocity and local identity into peasant social capital institutions and to take advantage of the changes in the national context, establishing a protective umbrella for this embryonic social capital.

Although building formal institutions for participation was part of their work, a much more important factor was their impact on informal institutions (see figure 1), which, as noted by Putnam (1993a), penetrate the formal institutions and often turn their real operation against democratic development. The introduction of semi-clientelism in a context of new opportunities weakened authoritarian clientelism. Community social capital arose from the synergy between this semi-clientelism and the precursors of reciprocity in the local descent groups; at the time it also helped to weaken authoritarian clientelism in the area, with the emergence of peasant social actors at the regional level and the resulting democratization of relationships in the region.

\section{Alternative cultural repertoires and norms}

In more general terms, the experience in Chiquimula suggests that some modifications should be made in the view of cultural determinism and negative social equilibria that forms part of the theoretical framework of social capital posited by Putnam and others.
For Putnam, cultural norms of distrust and dependence are rigid traditions which resist structural changes in formal institutions. However, the peasants in Chiquimula proved to have a very broad cultural repertoire, with alternative norms that included not just distrust and dependence but also norms of autonomous action and accountability to their kin groups and communities.

Both North and Putnam recognize that there are feedback mechanisms between social and cultural subsystems, but the main thrust of their arguments concerning social capital is fundamentally deterministic, ascribing almost all forms of behaviour to cultural factors. Putnam draws a universal conclusion from his Italian case study, asserting that there are "two social equilibria": the equilibrium of societies rich in social capital, and the equilibrium of those characterized by distrust, betrayal and authoritarianism (Putnam, 1993a, p. 177). The essence of this model -implicitly derived from economic equilibrium theory- is that "path dependence" means the constant strengthening of these two opposing sets of norms and practices whose directions became set in the past (Putnam, 1993a, p. 179).

However, rather than being coherent and immutable sets of rules and beliefs, cultures are constantly changing and include an enormous range or repertoire (Swidler, 1986) of alternative "sentences" that are no longer used and fragments of "sentences" which are reworked and recombined daily by persons and groups because of the need to adapt to the changes that cultures are constantly encountering in their environment. These alternative norms, which were kept submerged during the period of repressive authoritarian clientelism, resurfaced when the socio-political climate changed. When some leaders continued to exhibit passive and subjugatory "path dependent" attitudes, failing to take the initiative or continuing to seek personal gain from their role of nexus with the "outside world", the communities -especially the younger members- recalled these other traditional principles to them and either brought about changes in the leaders' behaviour or, in some cases, changed the leaders themselves. The existence of these alternative cultural repertoires also explains why some changes in the social structure (in this case, the disappearance of the system of "Comisionados Militares" and the emergence of reformist national elites) led to rapid changes in the norms on cooperation and social capital. 


\section{Co-evolution of strategies}

The second weak point in Putnam's argument against the possibility of rapid social capital building is the idea that "acivic" social systems always tend towards a negative equilibrium with a high degree of distrust and egoism. In Chiquimula, however, the regional socio-political system quickly ceased to be purely authoritarian and began to change into a system of semi-clientelism: into what complexity theory calls a "transition phase" to an agent-based system (Cowan and others, 1994). In this view, social systems never naturally tend towards equilibrium but instead there is a situation where the strategies of numerous agents constantly co-evolve, sometimes slowly, sometimes quickly, and social relationships and institutions "emerge" from this process (Arrow, 1994).

The systemic transition phase in Chiquimula marked the end of a period of slow change: the long period of authoritarian clientelism and repression. The new conditions gave rise to very rapid changes in the strategies and relations of both old and new actors, putting an end to path dependence and speeding up the formation of peasant social capital and its presence as a social actor in the region (figure 1).

Accelerated co-evolution of the social actors' strategies began in early 1997, when PROZACHI and FIS encouraged the formation of committees for the coordination of rural community organizations at the municipal level. Authoritarian mayors and their par-

FIGURE 1

Chiquimula (Guatemala): Changes in the informal institutional structure in projects with peasant participation

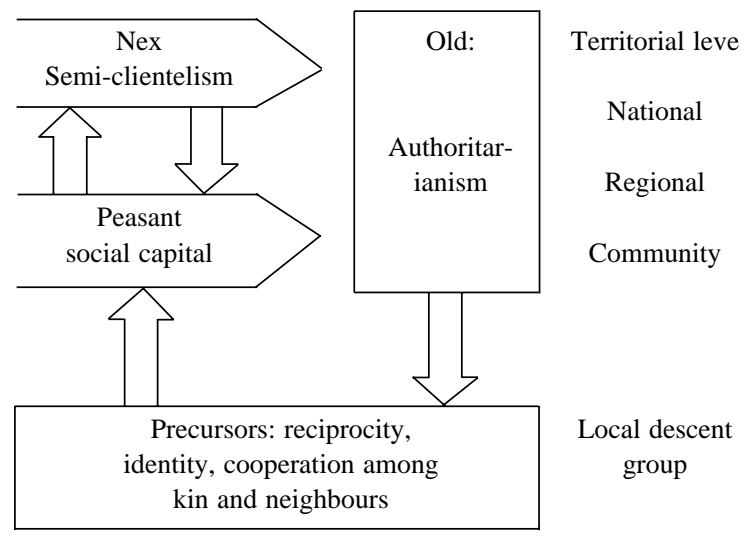

ties co-opted these committees through the participation of local and national government functionaries on the directorates of these committees, but in some municipalities the villagers reacted by proposing that those functionaries should be limited to an advisory role. The mayors complained about this strategy to the regional (Departmental) governor, to which the villagers reacted by boycotting the meetings of their own municipal coordination committees. Local FIS officials responded by proposing to the national government that the villagers' proposal be accepted. After this official legitimation, the villagers formed new municipal coordinating committees in which public officials were relegated to an advisory role. The mayors' strategies in response to this varied: some continued to oppose the dilution of their local control, but others allied themselves with these new social actors by providing space and transportation for their meetings. FIS began to channel its financial and technical support for social infrastructure construction directly through these more autonomous committees and community councils.

The equilibrium view of economic and social systems has been challenged by the newest versions of the theory of complex agent-based adaptive systems, applicable to a wide range of areas, from ecosystems to stock markets. This recent line of theory contains two basic challenges to Putnam's and North's dual equilibrium concept in complexity theory. Firstly, as Durlauf (1997) has pointed out, path dependence continues only until there is a new shock to the system. Such a shock may be initially small, but if it changes the opportunity structure for different kinds of actors, the resulting changes in their behaviour can end up by erasing old paths and tracing new ones. Secondly, Arrow (1994) argues that complexity theory has shown that economic and social institutions are not the result of planning or a tendency towards equilibrium but emerge from the co-evolution of the strategies of numerous agents who interact both to compete and to cooperate. A system may thus exhibit a temporary stable state until a critical mass of agents perceive change, opt for new strategies, and find ways to implement them that fit in with others' strategies. These changes in strategies can produce a phase transition in the system in which very rapid institutional change opens up new directions, as contrasted with the slow, unidirectional reinforcing changes that occur while path dependence obtains. 
In Chiquimula, the emergence of social capital originated in both cultural messages and structural changes. On the one hand, the pro-cooperation proselytizing of PROZACHI staff struck old but familiar chords concerning good neighbourliness and the imperatives of diffuse reciprocity, while the message of peace and democracy brought new ideas that struck against the established relations of authoritarian clientelistic structures. As a result, leaders began to take the initiative rather than waiting for orders from above, and younger persons began to reject corrupt authoritarian local "brokers", reminding them and the community of the old rule that their first loyalty should be to their own people.

Any kind of change in the balance of power among national political elites can open up the possibility of ending path dependence in authoritarian clientelistic structures. Thus, the emergence of new forms of semi-clientelism is not necessarily associated exclusively with progressive reformists, since even relatively conservative reformists can find reasons to ally with local base groups. Both such types of reformists played their part in the rapid transition that took place in Chiquimula in the mid-1990s.

The transition from an authoritarian to a semi-clientelistic system in the region involved an acceleration of social actors' reactions and the adaptation of their strategies, after an initial phase of slow change, and led to the emergence of new norms, forms of behaviour and relationships which hastened the consolidation of peasant social capital and, in essence, set up a new institutional context in the region.

This strengthening of peasant social capital was a chain of action and reaction among at least three main social actors: the provincial urban elites, outside anti-poverty agencies, and the hillside communities themselves. The history of the construction of peasant social capital in Chiquimula is also, then, the history of the creation of a new social actor and a transition from the norms, forms of behaviour and relationships typical of authoritarian clientelism to those of semi-clientelism.

Such a change was possible only because hillside village communities had already built (or rebuilt) their rudimentary social capital at the beginning of this process and could therefore intervene and adapt as social actors, reacting to the strategies of their opponents and allies alike. While not the ideal environment for peasant social capital, semi-clientelism tolerated its existence and allowed room for its strengthening and accumulation.

\section{Stages in the evolution of the social actors' strategies}

The co-evolution of the social actors' strategies in Chiquimula over the seven-year period studied here can be divided into four main stages:

\section{a) Slow change with authoritarian clientelism (1991-1993)}

In this first stage, clientelistic political parties and local economic elites dominated the population through authoritarian clientelistic systems, with support from the military; the anti-poverty agencies limited their actions to the technocratic provision of services to passive beneficiaries in the villages, in a relatively steady state of the regional system.

\section{b) Incipient transition phase (1993-1996)}

This stage began when PROZACHI decided to change its strategy, promoting embryonic peasant economic organizations around small production and marketing groups and encouraging grass-roots participation in project planning through the core groups, within the protected environment of Project activities and with short-term material benefits to participants.

Clientelistic political parties reacted by expressing alarm through local political caciques, but although Project personnel were sometimes changed, PROZACHI was able to continue its new activities because of alliances with national reformist groups. Hillside villagers slowly began to cooperate among themselves and cultivated an alliance with PROZACHI, which, in turn, intensified training in organizational skills at the request of the villagers.

\section{c) Accelerated co-evolution of actors' strategies (1997)}

Early in 1997 PROZACHI and FIS encouraged the formation of both inter-village councils and municipal coordinating committees for those councils.

In February and March 1997, FIS trained and supported peasant organizations in the presentation of proposals for the financing of social and productive infrastructure projects.

In April-June 1997 village organizations met to form municipal coordinating committees. Clientelistic political parties co-opted most such committees through the participation of local and national gov- 
ernment functionaries on their directorates, to which the villagers reacted by proposing that such functionaries should be limited to an advisory role. In response, the political parties protested through the mayors to the regional (Departmental) governor, alleging that such limitations on the functionaries would be illegal. After the villagers reacted by boycotting municipal committee meetings, local FIS officials proposed to the national government that the villagers' proposal should be accepted, and a regional seminar was held by FIS, with the participation of functionaries of the Governor's office and the municipalities, to explain the benefits of this approach in the context following the signing of the peace accords.

\section{d) Emergence of semi-clientelism (1997-1998)}

In mid-1997 the village councils formed new municipal coordinating committees in which public officials were relegated to an advisory role. The mayors' strategies in response to this varied: some flatly rejected this innovation, but others allied themselves with these new social actors, providing them with transportation and premises for their meetings. FIS channeled financial support directly to these autonomous councils.

In late 1997 and early 1998 one political party requested a peasant organization's support for its mayoral candidate. The organization refused, however, because it had not participated in the process of selection of the candidate.

\section{IV}

\section{Conclusions}

\section{Is it possible to construct social capital?}

Does the experience of PROZACHI and FIS show that it is possible to construct social capital where "acivic" norms and practices predominate? The answer depends in part on whether the achievements described above constitute social capital according to the strict definition given at the beginning of this article: i.e., institutions based on trust and cooperation that constitute economic public goods or that contribute to the civic public good. In the case of Chiquimula -although the question of economic ben-
In mid-1998 eight municipal coordinating committees joined together to create a regional organization. PROZACHI subcontracted road repair and other services to the new organization. Local village organizations began to take more initiatives, proposing infrastructure projects and participating in school co-management schemes. A peasant leader ran successfully for a position as member of a municipal council. The regional peasant organization asked PROZACHI for the loan of its heavy road-making machinery. PROZACHI initiated a new phase (PROZACHI-2) in which local, municipal and regional peasant organizations participate in a co-management process aimed at achieving the autonomous institutional sustainability of the organizations and enterprises created between 1991 and 1998.

Thus, the rapid changes in actors' strategies in the transition phase and the resulting systemic modification are among the possible reasons for the relative rapidity with which peasant social capital was constructed in Chiquimula. Another important factor was the existence of methodologies for building community social capital which made it possible to achieve goals set intentionally. PROZACHI and FIS staff were thus able to prepare the neophyte social actors in the hillside villages in time for them to take advantage of the opportunities and challenges that emerged in the mid-1990s in Chiquimula: this standard methodology gave more rapid results than spontaneous changes or reliance on the side-effects of other kinds of public action (Putnam, 1993b).

efit calls for further research $-{ }^{6}$ he answer in the second case is "yes" (box 1).

First, the purposeful construction of peasant social capital achieved a (relatively) limited objective: the empowerment of hillside villagers as part of the

\footnotetext{
${ }^{6}$ Nevertheless, preliminary evidence indicates that access to inputs and markets, as well as productivity, improved for most peasant families. Some 200 new associative micro-enterprises were set up within the framework of PROZACHI, presumably with attendant savings of transaction costs, while market imperfections were reduced both in smallholder coffee wholesaling and in the local rural day-labour market.
} 


\section{BOX 1}

\section{SOME HYPOTHESES ABOUT BUILDING SOCIAL CAPITAL}

- Reciprocity norms and practices exist in small local groups everywhere. Cooperation and accountable leadership are a part of most modern human cultures as a result of multilevel selection; iteration of practices previously found to be satisfactory usually leads to cooperation.

- Cultures contain changing repertoires with contradictory content. Systemic change can come from culture or from social structure. Removal or reduction of repression allows social capital to re-emerge; complex systems do not tend toward equilibrium but change constantly through co-evolution of the strategies of different actors.

- Changes in national elites produce "windows of opportunity" for the emergence of local social capital. Alliances with reformist sectors in government open the way to social capital building.

- Trust, cooperation, shared identity and reciprocity created in the community can be replicated among leaders in order to "scale up" social capital from small communities to the regional level.

- Methodologies and techniques now exist that make possible the construction of social capital intentionally, rather than as a side-product of other activities or as a spontaneous phenomenon.

effort to achieve a sustainable reduction of poverty. Second, this empowerment involved the constitution of a new social actor in the area, incorporating into civic affairs a social sector previously excluded from public decision-making, which in itself represents a strengthening of local and regional democracy in Guatemala. Third, the consolidation of peasant territorial organizations led to a rapid transition from a repressive, authoritarian structure to a semiclientelistic system in flux, which constitutes a step forward towards the establishment of a strong regional civil society and opens the way for further advances in this direction.

The basic intention of this study has been to show how and why, in one empirical case, the theoretical proposition that building social capital from scratch is always a slow, nearly impossible task did not hold good. Analysis of this experience also suggests some possible revisions to social capital theory and some conclusions on policies and measures in the field of rural community empowerment. The suggested measures for promoting community social capital are summarized in box $2 .^{7}$

\footnotetext{
${ }^{7}$ A number of the suggestions set forth in box 2 were incorporated in the design of "PROZACHI-2", a new project (1998-2002) to consolidate and ensure the institutional sustainability of peasant self-management in the area, which is being supported by the Government of the Netherlands.
}

\section{Final remarks}

In the final analysis, the stereotype view of peasant culture in Chiquimula does contain an element of truth. It is indeed a relatively individualistic culture marked by dependence and domination, yet paradoxically at the same time it is a culture with a broad and dynamic repertoire of varied norms, including some which can serve as the symbolic basis for supportive and reciprocal practices. Chiquimula seemed to lack social capital institutions, but only until the institutional practices of the past were rescued and contexts and opportunities favourable for the development of new group strategies arose.

Path dependence proved to be less of an obstacle to peasant social capital building than the cultural obstacle represented by authoritarian clientelism, since it quickly gave way to the changes brought about in the political structure by the presence of new social actors in Chiquimula and the peace accords.

Although there was an apparent absence of social capital in the hillside villages, in reality there were important precursors of cooperation which were utilized through the initial restriction of PROZACHI's activities to the local descent group level, with subsequent extension to the community, municipal and regional levels. An exercise of "social capital archaeology" revealed memories of the past successes of a previous generation. 


\section{BOX 2}

\section{MEASURES FOR BUILDING RURAL COMMUNITY SOCIAL CAPITAL}

- Search for submerged norms and practices of trust, reciprocity and cooperation in local descent groups in peasant cultures apparently dominated by individualism and "familism".

- Analyse and take advantage of favourable conditions for the resurgence of social capital created by the weakening of authoritarian clientelism.

- Carry out an "archaeological dig" for social capital in order to identify previous social capital development experiences that have been repressed or discouraged, but that are preserved in the collective oral historical memory.

- Initiate social skill building in local descent groups consisting of no more than 10-15 households united by kinship, residence and practice of reciprocity. Make sure that most such groups, not just dominant factions, are represented in community-wide exercises to develop social capital.

- Provide repeated opportunities at the community level for the creation of ties of familiarity and cooperation.

- Provide "cushioning" from regional authoritarian clientelism (both political and economic) for embryonic peasant associations while the social skills of their leaders are honed and conflicts due to factionalism in the associations are overcome.

- Be alert for minor shocks to systems of authoritarian clientelism that can weaken negative path dependence and open windows of opportunity for the resurgence of peasant social capital.

- Develop rapid response capacity in projects and programmes to counteract moves by clientelistic actors in transition phases and foment strategic negotiating capabilities among peasant leaders.

- Give priority to promoting a sense of mission among project personnel in favour of the development of autonomous social capital.

- Promote open discussion of interpersonal networks that cross the boundaries between the government and civil society. Facilitate access of excluded communities to connections that provide the information and services already enjoyed by more integrated strata.

- Take steps to ensure that civic social capital in poor communities offers short-term material benefits as well as gains in terms of political empowerment.

The emergent peasant social actors, with the support of outside institutional allies, took advantage of the opportunities created by the changes that took place in the national elites, participated in the rapid co-evolution of the strategies of various local social actors, and helped to lay the foundations for a new semi-clientelistic structure in the region which was more favourable to the development of democratic and participatory civil society.

\footnotetext{
${ }^{8}$ With regard to organizational management training methods, see World Bank (1997), Cruz (1996), IAF (1995), RIMISP (1996 and 1998), Rivera (1996), Toledo (1994) and Torres (1998).
}

The application of the existing organizational management training methods ${ }^{8}$ and the buffer role played by the development projects made possible the purposeful construction of social capital, in contrast with Putnam's claim that this is always a side-effect of public actions aimed at other objectives. It was the above-mentioned combination of factors which made possible the construction of peasant community social capital in Chiquimula. Regardless of whether or not this community social capital succeeds in bringing the expected benefits (savings on transaction costs, creation of public goods and the establishment of a strong civil society), it is beyond question that it was possible to create this capital in the space of only a few years. 
The present study suggests that, out of the six factors identified as forming bases for social capital building in Chiquimula, three were of key importance: the existence of forms of reciprocity in peasant culture; the emergence of a climate of changes favourable to the formation of peasant social actors, and the internalization of community self-management capabilities.

Everything seems to indicate that there is no such thing as intrinsically "acivic" rural communities which totally lack the potential for social capital building, but such potential may be buried in past memories and in parts of the cultural repertoire which are currently in disuse. It should however be acknowledged that the particular forms of reciprocity in a community may be different from those existing in Chiquimula, which are based on kinship in relatively stable local descent groups. Even in such cases, however, there may be other forms of reciprocity, associated with other forms of kinship, which can be used as cul- tural and social bricks for building community social capital institutions (box 2).

Furthermore, although the changes in the political context in Chiquimula were particularly rapid and dramatic, there have been cases in other countries where seemingly minor changes have sparked off unexpectedly dynamic processes of strengthening of embryonic social actors. Any change in the configuration of the elites and the political ethos can serve as a "window of opportunity" permitting the construction of social capital.

Finally, in some cases self-management and political participation capabilities have been developed by the communities themselves, without much outside help. However, the dual function played by outside agents -as providers of the methods available in this field and as protective shields during the formation of new social actors on the local scene- is essential to allow peasant social capital to develop quickly and securely.

(Original: English)

\section{Bibliography}

Arrow, K. (1994): Beyond general equilibrium, in Cowan and others, Complexity: Metaphors, Models and Reality, Reading, Massachusetts, Santa Fe Institute/Addison-Wesley.

Axelrod, R. (1997): The Complexity of Cooperation, Princeton, New Jersey, Princeton University Press.

Bebbington, A. (1998): Sustaining the Andes? Social capital and policies for rural regeneration in Bolivia, Mountain Research and Development, vol. 18, No. 2, Berkeley, California, University of California Press.

Coase, R. (1937): The nature of the firm, Economica. New Series, No. 4.

Cowan, G. and others (1994): Complexity: Metaphors, Models, and Reality, Santa Fe, New Mexico, Santa Fe Institute.

Cruz, J. L. (1996): Estrategia complementaria y de coordinación del proceso organizacional para el desarrollo comunitario, Chiquimula, Guatemala, Proyecto de Desarrollo Rural para Pequeños Productores en Zacapa y Chiquimula (PROZACHI).

Durlauf, S. (1997): What Should Policymakers Know About Economic Complexity?, Working paper, Santa $\mathrm{Fe}$, New Mexico, Santa Fe Institute.

Durston, J. (1992): Una mirada al Proyecto Zacapa-Chiquimula desde la perspectiva de las ciencias sociales, mission report, New York, UN Office of Project Services/ PROZACHI.
-(1998): Building social capital in rural communities (where it doesn't exist): Theoretical and policy implications of peasant empowerment in Chiquimula, Guatemala, paper presented at the 1998 Meeting of the Latin American Studies Association (LASA), Chicago, Illinois, 24-26 September.

Evans, P. (1996): Government action, social capital and development: Reviewing the evidence on synergy, World Development, vol. 24, No. 6, Washington. D.C., The American University.

Firth, R. (1963): Elements of Social Organization, Boston, Massachusetts, Beacon.

FLACSO (Latin American Faculty of Social Sciences) (1993): Descripción cualitativa de procesos sociales: el área de Quetzaltepeque, Guatemala City.

Foster, G. (1961): The diadic contract: A model for the social structure of a Mexican peasant village, American Anthropologist, vol. 63, Washington, D.C.

Fox, J. (1996): How does civil society thicken? The political construction of social capital in rural Mexico, World Development, vol. 24, No. 6, Washington. D.C., The American University.

Galeano, L. and M. Yore (1994): Poder local y campesinos, Asunción, Centro Paraguayo de Estudios Sociológicos.

IAF (Inter-American Foundation) (1995): Inter-American Foundation Case Studies in Grassroots Development, Arlington, Virginia. 
IFAD (International Fund for Agricultural Development) (1998): PROZACHI: La historia de un proyecto para el desarrollo de pequeños productores en Zacapa y Chiquimula, Rome, IFAD/ Ministerio de Agricultura y Ganadería (MAGA).

Lundius, J. (1998): Takarop: The Story of a Development Project Among Peasants in Zacapa and Chiquimula (summary), Rome, IFAD.

Mauss, M. (1990): The Gift: The Form and Reason for Exchange in Archaic Societies, New York, Norton.

Mayer, A. (1966): The significance of quasi-groups in the study of complex societies, in M. Banton (ed.), The Social Anthropology of Complex Societies, London, Tavistock.

Metz, B. (1998): Without nation, without community: The growth of Maya nationalism among Ch'ortís of Eastern Guatemala, Journal of Anthropological Research, vol. 54, No. 3.

North, D. (1990): Institutions, Institutional Change and Economic Performance, Cambridge, Massachusetts, Cambridge University Press.

Portes, A. (1998): Social capital: Its origins and applications in modern sociology, Annual Review of Sociology, No. 24.

Portes, A. and P. Landholt (1996): The downside of social capital, The American Prospect, No. 26.

PROZACHI (1995): Planificación participativa, Chiquimula, Guatemala.

Putnam, R. (1993a): Making Democracy Work: Civic Traditions in Modern Italy, Princeton, New Jersey, Princeton University Press.

(1993b): The prosperous community: Social capital and public life, The American Prospect, No. 13.
RIMISP (Red Internacional de Metodologías de Investigación de Sistemas de Producción) (1996): Intercambio de experiencias sobre el papel de las organizaciones campesinas en el manejo de problemas y oportunidades de desarrollo agrícola, paper presented at the Taller Electrónico, 2 September-31 October, http://www.fidamerica.cl/conferen. htm.

-(1998), Transferencia de proyectos de desarrollo agrícola y rural a los usuarios, Conferencia Electrónica, 13-31 July, http://fidamerica.cl/ conferen.htm.

Rivera, R. (1996): Desarrollo rural sustentable: manual para la elaboración de proyectos, Caracas, Nueva Sociedad.

Swidler, A. (1986): Culture in action: Symbols and strategies, American Sociological Review, vol. 51, No. 2, American Sociological Association.

Tendler, J. (1997): Good Government in the Tropics, Baltimore, Maryland, Johns Hopkins Press.

Toledo, V. (1994): Planificación participativa del desarrollo local: guía metodológica, Temuco, Chile, Regional Secretariat for Planning and Co-ordination (SERPLAC).

Torres, V. H. (1998): Sistema de desarrollo local SISDEL: la participación comunitaria y vecinal en la formulación, seguimiento y evaluación de proyectos, Quito, Abya-Yala.

Wilson, D. S. (1997): Human groups as units of selection, Science, vol. 276, Washington, D.C., American Association for the Advancement of Science.

Wolf, E. (1966): Peasants, Englewood Cliffs, New Jersey, Prentice-Hall.

World Bank (1997): The World Bank Participation Sourcebook,ttp://worldbank.org/html/edi/sourcebook/. 